Sección temática Anhelos de libertad. Del esclavo al liberto

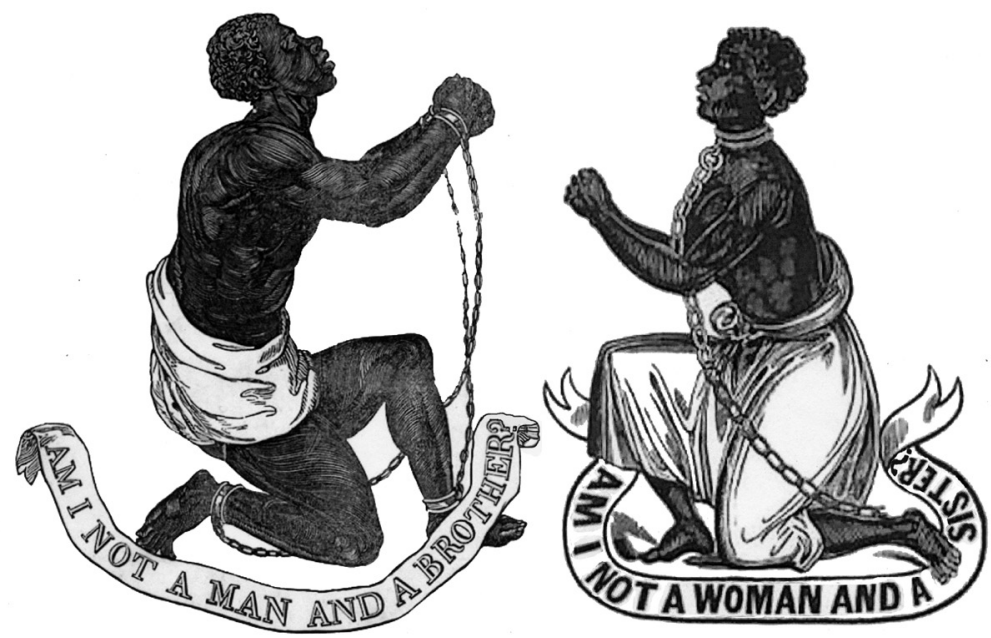




\title{
Libertos, vagos y bandoleros. La reglamentación del trabajo tras la abolición de la esclavitud (Cuba, 1886-1895)
}

\author{
Imilcy Balboa Navarro* \\ UNIVERSITAT JAUME I
}

En 1886 llegaba a su fin el sistema de trabajo esclavo en la isla. La liberalización del mercado laboral comportó el establecimiento de un nuevo tipo de relaciones entre los dueńos y los trabajadores, de manera que los segundos se integraran en la lógica de las relaciones capitalistas. Las contratas y los salarios-como vía de control y regulación de la disciplina- habían asegurado la sujeción de la fuerza laboral durante la transición. En la etapa posterior, la estrategia de los propietarios azucareros insistió en los mismos postulados, a las contratas y los salarios se añadió la lucha contra la vagancia y el bandolerismo. Las leyes contra la vagancia permitieron el control de los que no aceptasen las condiciones de trabajo y quedaran al margen de las reglas del sistema, mientras que los salarios continuaron actuando como mecanismos de sujeción y mantuvieron atados a los trabajadores al ingenio. Como resultado, a pesar de haber obtenido la libertad las condiciones de vida y trabajo de los antiguos esclavos apenas sufrieron variación y continuaron ocupando un lugar subordinado en la sociedad.

(Cuba, abolición de la esclavitud, relaciones laborales, patrocinados, vagos)

\footnotetext{
1 decreto de abolición de la esclavitud, promulgado el 13 de febrero de 1880, sustituyó la esclavitud por el patronato. Un cambio, que atendía solo a la denominación externa, pues aun cuando los amos fueron llamados en adelante patronos y los esclavos patrocinados, en realidad se conservaron intactas las relaciones fundamentales del régimen. ${ }^{1}$
}

*ibalboa@his.uji.es El presente trabajo se inscribe en los proyectos de investigación del Ministerio de Ciencia e Innovación (HAR 2009-07037) y Bancaixa-UJI (P1-1A 2008-08).

${ }^{1}$ Véase la Ley y Reglamento de Abolición en Fernando Ortiz, Los negros esclavos, La Habana, Ciencias Sociales, 1987, 467-487. Al respecto véanse Rebecca Scott, La eman- 
El patronato, o lo que lo es mismo, la continuación de la esclavitud bajo una nueva designación le proporcionó a los dueńos de esclavos, el tiempo necesario para crear -y con éxito- los mecanismos de transición hacia el trabajo libre. ${ }^{2}$ En el periodo anterior junto al trabajo de los esclavos devenidos patrocinados se habían ensayado los mecanismos que les permitirían el control de la mano de obra y del mercado laboral en las áreas rurales. Algunos con menos fortuna como ocurrió con la importación de indios de Centro y Sudamérica y la inmigración de peninsulares. Otras, como las contratas de asiáticos, arrojaron mayores resultados y cumplieron su objetivo.

En 1886, apenas se contabilizaban unos 25 mil patrocinados laborando en las plantaciones azucareras, por lo que los hacendados azucareros de la isla aceptaron la supresión del sistema -que llegaría con el Real Decreto de 7 de octubre de 1886- dos años antes de cumplirse el plazo estipulado por la ley de 1880 .

En el periodo posterior, al instaurarse definitivamente las relaciones capitalistas en la agricultura, a los mecanismos de coerción indirecta, como los salarios y las contratas, se sumaron una serie de disposiciones que tenían como objetivo sujetar a los expatrocinados al trabajo. Allí donde dichas medidas no fueron efectivas, se aplicaron entonces las destinadas al control de la vagancia para reconducir a los que se encontraban fuera del mercado de trabajo.

En el presente texto estudiaremos como fue la integración de los antiguos esclavos en las áreas rurales en los años posteriores a la abolición de la esclavitud. Las bases sobre las que se organizó el mercado laboral en las nuevas condiciones del trabajo libre y las medidas implementadas tanto por el gobierno como por los hacendados para asegurar la continuidad del trabajo de los antiguos esclavos. Así como las condiciones de contratación, trabajo y vida en las plantaciones azucareras en los años posteriores a 1886, cuyo re-

cipación de los esclavos en Cuba. La transición al trabajo libre, 1860-1899, México, Fondo de Cultura Económica, 1989. También Imilcy Balboa, "El camino a la libertad. Los patrocinados en las áreas rurales. Cuba 1878-1886”, Espace Caraïbes Amériques, París, Université des Antilles-Guyane, 2000, 77-96.

${ }^{2}$ La ley establecía un tope de ocho años para la supresión definitiva del sistema esclavista. 
sultado contribuyó a sujetar a los antiguos esclavos a las plantaciones aún después de haber obtenido la libertad legal.

\section{UNIFICAR Y REGULAR EL MERCADO LABORAL, I 886}

Cuando a fines de julio de 1886, el Ministro de Ultramar pidió la opinión de las principales corporaciones de la isla -la Junta de Agricultura, Industria y Comercio de La Habana y el Círculo de Hacendados- sobre la conveniencia de poner fin al sistema de patronato, ${ }^{3}$ ambas corporaciones se mostraron partidarias de acelerar la extinción de la esclavitud y unificar el mercado laboral bajo las nuevas condiciones.

La Junta de Agricultura, Industria y Comercio de La Habana consideraba beneficiosa la abolición inmediata en tanto ayudaría a normalizar la condición de los trabajadores y la regulación de los jornales, pues -en su criterio- el trabajo de braceros de diferente condición -patrocinados, contratados, libres, etcétera-impedía establecer una contabilidad agrícola más clara. Calificaban de error el empleo hasta ese momento de hombres de "razas inferiores" mal pagados -léase asiáticos-, por los cuales se adelantaban grandes sumas que finalmente representaban el valor de esos mismos jornales abonados por adelantado, por lo cual resultaban más caros que si los hubiesen ido satisfaciendo a medida que los necesitaban.

En contraposición a la idea generalizada entre los productores sobre la falta de brazos, estimaba que los trabajadores existentes en las áreas rurales eran suficientes no sólo para la industria azucarera, sino también para garantizar el refuerzo laboral en el resto de las manufacturas.

Argumentaban que la emancipación había contribuido a borrar el estigma del trabajo esclavo para las faenas agrícolas en los inge-

${ }^{3}$ Debían responder cuatro puntos: $1^{\circ} \mathrm{Si}$ era urgente declarar la abolición, 20 Qué número de trabajadores estaban empleados en las faenas agrícolas y a qué raza pertenecían, $3^{\circ}$ El salario que recibían y $4^{\circ}$ Cuántos trabajadores eran necesarios. Véanse "Informe de la Junta Provincial de Agricultura y Comercio de La Habana”, 7 de agosto de 1886 e "Informe del Círculo de Hacendados", 7 de agosto de 1886, Archivo Histórico Nacional, Madrid (en adelante AHN), Fondo Ultramar, Sección Fomento, Leg. 280, núm. 2. 
nios, por lo que muchos hombres blancos se estaban dedicando a estas labores, aunque todavía la mayor parte de los braceros pertenecían a la raza negra. El informe concluía afirmando que: "dado el escaso número de los que están todavía en estado intermedio, ni el propietario pierde gran cosa con renunciar al escaso valor que para su redención tiene hoy el patrocinado ni es comparable este sacrificio con el bien que le resultará al país de llegar cuanto antes a que la condición de todos nuestros labradores sea la de hombres libres". ${ }^{4}$

La abolición tampoco constituía un problema preocupante para los dueños de ingenios. A la reunión convocada por la Junta Directiva del Círculo de Hacendados apenas asistieron siete de sus miembros y en el informe final emitido en respuesta a la consulta del gobierno, sólo se limitaron a reiterar las peticiones que venían solicitando desde la entrada en vigor del patronato: inmigración y reformas.

De ahí que se declararan partidarios de la abolición siempre que viniera precedida de una ley que asegurase el trabajo y les proporcionase una inmigración numerosa. Mientras que las reformas fueron entendidas en su sentido más amplio. La extinción del trabajo esclavo fue utilizada como pretexto para solicitar un cambio en las condiciones de la inmigración, la variación de los aranceles o el sistema impositivo, así como el establecimiento de nuevas bases para las relaciones comerciales sobre todo con Espańa y Estados Unidos. Sin olvidar las relaciones políticas. ${ }^{5}$

Ambas corporaciones coincidían en las estimaciones acerca del total de trabajadores existentes en los campos: aproximadamente 200 mil, con ligeras diferencias en cuanto a la composición racial. Según la Junta, los antiguos esclavos -70 por ciento- constituían el grupo más numeroso, en segundo lugar se ubicaban los trabajadores blancos -30 por ciento-y por último unos 10 mil chinos, organiza-

4 "Informe de la Junta Provincial de Agricultura y Comercio de La Habana", 7 de agosto de 1886, AHN, Ultramar, Fomento, Leg. 280, núm. 2.

5 "Informe del Círculo de Hacendados", 7 de agosto de 1886, AHN, Ultramar, Fomento, Leg. 280, núm. 2. Sobre las peticiones de los hacendados véase Imilcy Balboa, "Brazos para el azúcar. Reformas, centralización e inmigración. Cuba 1820-1866", en José Antonio Piqueras, Azúcar y esclavitud en el Caribe en el final del trabajo forzado, Madrid, Fondo de Cultura Económica, 2002, 50-75. 
dos en cuadrillas. Para el Círculo, la distribución del contingente laboral era como sigue: 100 mil de color libres y 25 mil patrocinados, 45 mil blancos, 30 mil asiáticos.

Si bien, la Junta consideraba suficientes el número de trabajadores existentes, los hacendados a través del Círculo señalaban que las necesidades de la agricultura quedarían cubiertas con unos $100 \mathrm{mil}$ trabajadores -la mitad de los existentes-, eso sí, especificaban que solo "de momento" y a renglón seguido concluían solicitando que en el futuro esa cifra se elevara a 500 mil, de los cuales 400 mil debían de ser blancos, y el resto filipinos o asiáticos. Llama la atención que los hacendados, hasta ese momento defensores decididos de la esclavitud, precisamente cuando se estaba planteando el paso hacia el trabajo libre, apoyasen la inmigración blanca, aunque no renuncian a los trabajadores asiáticos o filipinos, "aceptando la china en último caso por la urgencia que el país tiene de trabajadores agrícolas" ${ }^{6}$

Los dueños de ingenios se habían mostrado a lo largo del siglo, contrarios al pago de un salario, máxime si tenemos en cuenta que las prácticas consustanciales a la esclavitud habían viciado las relaciones laborales y elevado el coste del trabajo libre. ${ }^{7}$ En su creencia, procurarse brazos baratos era una de las mejores formas de rebajar costes, $\mathrm{y}$ para lograrlo habían recurrido a la contratación de asiáticos, indios yucatecos e incluso se plantearon importar negros libres de las colonias inglesas del Caribe, al igual que peninsulares y canarios. ${ }^{8}$ Aunque

6 "Informe del Círculo de Hacendados", 7 de agosto de 1886, AHN, Ultramar, Fomento, Leg. 280, núm. 2. Los criterios racistas acerca de la inmigración en Consuelo Naranjo y Armando García, Racismo e inmigración en Cuba en el siglo XIX, Madrid, Doce Calles, 1996. "El análisis de los factores socio económicos en Balboa", Imilcy Balboa, Los brazos necesarios. Inmigración, colonización y trabajo libre en Cuba, 1878-1898, Valencia, Centro Francisco Tomás y Valiente uned Alzira-Valencia, Fundación Instituto de Historia Social, 2000.

${ }^{7}$ Véase Juan Pérez de la Riva, Para la historia de las gentes sin historia, Barcelona, Ariel, 1976, 26-34. Laird Bergad, "The economic viability of sugar production based on slave labour in Cuba, 1859-1878”, Latin American Research Review, núm. xxiv/1, 1989, 95-115.

${ }^{8}$ Sobre la inmigración asiática véanse Juan Pérez de la Riva, "Demografía de los culíes chinos en Cuba, (1853-1874)" y "La situación legal del culí en Cuba", en El Barracón y otros ensayos, La Habana, Ciencias Sociales, 1975, 469-507 y 209-245. También Consuelo Naranjo e Imilcy Balboa, "Colonos asiáticos para una economía en expansión: Cuba, 1847-1880”, Revista Mexicana del Caribe, núm. 8, año Iv, Quintana Roo, 1999, 33-63. La entrada de yucatecos en Paul Estrade, "Los colonos yucatecos como sustitutos 
cambiara el color de la piel, las contratas de unos y otros estaban destinadas a un mismo fin: a) garantizar la rentabilidad; b) rebajar los costes; y c) incrementar la oferta de brazos.

Tales consideraciones mantuvieron su vigencia durante la transición al trabajo libre. Más allá de los aspectos cuantitativos, el centro de la cuestión se situó en el modelo a seguir en las relaciones entre los patronos y sus trabajadores. Los objetivos de los dueños de ingenios estuvieron encaminados, entonces, a alcanzar una corriente continuada de inmigración capaz de proporcionar el número de brazos suficientes para llenar las necesidades de la agricultura, forzar una baja en los jornales y lograr el mayor control posible sobre la fuerza laboral. De ahí las diferencias que apreciamos a la hora de reseñar los jornales que se estaban pagando a los braceros. Las estimaciones de la Junta fluctuaban a la baja, entre 1.0 pesos y 1.50 pesos en Billetes de Banco ( 0.45 centavos o 0.70 centavos de pesos oro) al día, cantidad que consideraban suficiente para el mantenimiento de un trabajador. En contraposición las cifras ofrecidas por el Círculo de Hacendados variaban según las localidades entre 25 y 40 pesos oro durante la zafra y de 15 a 25 pesos en billetes durante el tiempo muerto, sin incluir manutención.

Por su parte, la Real Sociedad Económica de Amigos del País, que no estaba contemplada entre los organismos consultados, emitió también un informe dirigido a su homónima madrileña con la intención de que su directiva lo diera a conocer en España. ${ }^{?}$

de los esclavos negros", Consuelo Naranjo y Tomás Mallo Gutiérrez, eds., Cuba la perla de las Antillas, Madrid, Doce Calles, 1994, 93-105. Las contratas de peninsulares en Fe Iglesias, "Los contratados peninsulares a Cuba", Anuario de Estudios Americanos, núm. 2, tomo LI, Sevilla, 1994, 93-112. También Carmen Barcia, "Los proyectos de población blanca y la Real Sociedad Económica de Amigos del País”, Espacies Caräibes, núm. 2, Université des Antilles et Guyane, París, 1994, 111-130 y Julio Le Riverend, Historia Económica, La Habana, Instituto Cubano del Libro, 1971, 341-343 y 347.

${ }^{9}$ Cabe destacar que el informe de la SEAP fue el más detallado. Consideraban las cifras aproximadas, pero las más cercanas a la realidad. En cuanto a los asiáticos basaban sus cálculos en el número de chinos inscritos en el Consulado General de esa nación, donde figuraban 23,800 , más de la mitad trabajaba en el servicio doméstico, la pequeña industria y el comercio al por menor en las ciudades y pueblos. "Informe de la Real Sociedad Económica de Amigos del País de La Habana”, 21 de agosto de 1886, AHN, Ultramar, Fomento, Leg. 280, núm. 2. 
Esta institución -al igual que la Junta de Agricultura-abogaban por la unificación del estatus de los trabajadores, que permitiría -en su criterio- igualar los jornales, y con ello aumentar la competitividad de la industria. En el número total de trabajadores -200 miltodos coincidían, divididos en 25 mil patrocinados, 10 mil chinos, 50 mil blancos y el resto de color libres, procedentes en su mayoría de las antiguas dotaciones. El salario oscilaba entre 10 y 18 pesos oro al mes con deducción de los días no laborables. La variabilidad se establecía acorde a las épocas del año -durante la zafra o el tiempo muerto-y la localidad -teniendo en cuenta la cercanía o no a un área poblacional-. "Es sabido que en la época de zafra, que dura cinco meses, crece el jornal de los trabajadores, y que las exigencias de éstos aumentan o disminuyen según están más o menos próximas las fincas a los centros de población o pueblos de campo, a donde han afluido los libertos para disfrutar las ventajas de la vida social que antes desconocían por completo". ${ }^{10}$

En contraposición a los temores generalizados entre los productores sobre la escasez de trabajadores tras la abolición, consideraban cubierto el mercado de trabajo. Los libertos - explicaban- no sólo habían encontrado ubicación en el azúcar, sino también en los cultivos menores. Por último, en aras de lograr un mayor incremento de la producción recomendaban a los dueños de haciendas que potenciaran la aplicación de los adelantos científicos y el perfeccionamiento de la maquinaria; mientras que el Estado debía favorecer la inmigración blanca junto a reformas políticas y económicas que tendieran a "atraer" al inmigrante y fijarlo a la tierra.

Como hemos podido observar hasta aquí, en sentido general, en los informes remitidos por la Junta, el Círculo y la Sociedad Económica observamos diversidad de opiniones en la composición del contingente laboral y el salario percibido, que pudiera tener su explicación en la variabilidad de los jornales en relación con el tiempo y el espacio. Lo que contrasta con la unanimidad de criterios en cuanto a: a) la conveniencia de la abolición inmediata; b) el total de trabajadores dedicados a las faenas agrícolas, considerados por de- 
más suficientes; y c) la petición de potenciar la inmigración para saturar el mercado laboral y provocar una baja en los jornales. Sobre todo, el Círculo de Hacendados, portavoz de los intereses de los dueños de ingenios insistió en este último aspecto, lo que venía a poner de manifiesto las verdaderas preocupaciones de los dueños de ingenios en cuanto a la organización del mercado de trabajo libre: más trabajadores y menos jornales.

\section{LA EXTENSIÓN DE LOS MECANISMOS DE CONTROL}

$\mathrm{Al}$ instaurarse definitivamente las relaciones capitalistas en la agricultura con posterioridad a 1886, los instrumentos de control terminaron de perfeccionarse con la adición de nuevas disposiciones para asimilar a la masa de asalariados que se incorporaba al mercado laboral. Los dueños de ingenios equipararon libertad con vagancia, y concentraron sus esfuerzos en limitar la primera y contener la segunda.

Desde que se promulgó la Ley de Patronato, los hacendados azucareros habían logrado de España que la institución no muriera definitivamente y que aun después de obtener su libertad legal los antiguos esclavos siguieran sujetos a una serie de restricciones. Entre ellas, "la obligación de acreditar la contratación de su trabajo o un oficio u ocupación conocidos". ${ }^{11}$

Tal exigencia abarcaba un periodo de cuatro años. Durante ese tiempo, cada tres meses, los antiguos esclavos deberían presentarse ante el alcalde municipal de sus respectivas localidades para acreditar que tenían ocupación fija. Aquellos que no cumpliesen este requisito serían catalogados de vagos y destinados a servir en las obras públicas durante un mes si era la primera vez que cometían la falta, de dos a seis en caso de reincidir, y si volvían a infringir estarían en esta tarea por todo el tiempo que les faltase para completar el plazo establecido.

Esta medida se mantuvo aun después de la abolición definitiva y fue justificada por las autoridades con alusiones a los "saludables" hábitos de trabajo que robustecían el espíritu y desarrollaban el

${ }^{11}$ Véase el apartado noveno de la ley de 1880. La Ley y Reglamento en Fernando Ortiz, Los negros esclavos, La Habana, Ciencias Sociales, 1987, 467-487. 
sentido moral. En realidad, tanto el gobierno como los hacendados temían las consecuencias que pudieran derivarse de la emancipación total, aunque sus motivos fueran diferentes. Para el primero, dicho requerimiento resultaba beneficioso "porque el hombre dedicado a trabajar se dedica con más dificultades a la conspiración y con más dificultad también se entrega al robo y el pillaje”. Mientras que los segundos, pretendían garantizar la mano de obra en la agricultura, "pues si se consigue que un buen número de estos hombres se dediquen al trabajo, se conseguirá con ello una baja en los precios en los jornales". ${ }^{12}$

Al propio tiempo, durante la década del ochenta -coincidiendo con el proceso de abolición- adquirió gran fuerza en la isla el debate sobre la vagancia. Para el Círculo de Hacendados la mejor forma de asegurar que los patrocinados continuaran trabajando en las haciendas era mediante la adopción de una ley de vagos.

En 1885, un año antes de la de la supresión definitiva del régimen esclavista, los criterios de los dueńos de ingenios fueron recogidos por la Comisión de Colonización. El informe de esta Comisión partía de considerar las nocivas consecuencias de la vagancia para la sociedad con el aumento de los vicios y la criminalidad. Ante el temor de que con el fin del patronato aumentase el número de "vagos" terminaban declarando el verdadero objeto de la disposición: sujetar a los patrocinados al trabajo:

Éstos, por lo mismo que el trabajo constituyó hasta ahora su forzosa obligación, como además carecen de la educación necesaria para entender que, si esclavos podía aquel trabajo deshonrarles, como creyeron, libres es una obligación cuyo cumplimiento eleva y dignifica, tendrán durante algún tiempo, al menos, como la suprema dicha, como la prueba más acabada de su omnímoda libertad, la libertad de no hacer nada y se aumentará una nueva raza de vagos a la ya enorme hoy existente. ${ }^{13}$

12 "Consulta del Gobernador de La Habana sobre libertos que por no acreditar que trabajasen son destinados a obras públicas”, ANC, ME, Leg. 3640, exp. Bq.

13 "Proyecto de Decreto sobre prevención y represión de la vagancia", Madrid, 2 de mayo de 1885, AHN, Ultramar, Fomento, Leg. 280, núm. 2. 
Para el logro de este objetivo se proponía la adopción de una serie de regulaciones que les permitirían asegurarse el trabajo de la población en edad laboral. Se encomendó a los ayuntamientos la confección de un padrón donde se consignaran todos los libertos varones existentes en el término municipal, incluidos los que aún estaban bajo el patronato. Estarían considerados además, todos los hombres mayores de dieciocho ańos "blancos y de color", sin medios de subsistencia, profesión u oficio reconocido.

Aquellos que no pudiesen justificar ante las autoridades gubernativas la contratación de sus servicios, o el ejercicio de un oficio o arte, serían destinados a trabajar en las obras públicas o a contratarse con un particular por un periodo no menor de seis meses, en caso de reincidencia incluso podrían ser obligados a cambiar de domicilio dentro de los dominios españoles por espacio de uno a dos años. ${ }^{14}$ Ahora bien, estas regulaciones serían anuladas si el "culpable" pagase por él o terceras personas una fianza de mil pesetas en metálico. Por último, se recomendaba la creación en cada provincia de una Junta compuesta del gobernador civil (presidente), el comandante militar, un juez de primera instancia, dos adjuntos provinciales y el alcalde municipal, quien estudiaría los casos y propondría al capitán general las medidas que con arreglo a estas bases deberían ser adoptadas.

La existencia de una población superflua que no podía ser absorbida por el sistema productivo y era susceptible de integrarse al contingente de vagos constituía un signo de alerta acerca del desempleo y no sobre la carencia de trabajadores. En realidad, cuando en 1886 los últimos patrocinados se incorporaban a las filas de los asalariados la situación de la isla era sumamente difícil. Sobre todo en las zonas rurales reinaba "la miseria y la falta de trabajo". La propia Junta de Agricultura Industria y Comercio de La Habana reconocía en agosto de ese ańo - dos meses antes de la abolición- que los salarios apenas permitían, a los trabajadores, adquirir lo imprescindible para subsistir, dada la carestía de los artículos de primera necesidad. El desempleo se estaba extendiendo y la prensa de la época daba cuenta 
de los trabajadores que marchaban a Panamá para laborar en las obras del canal por no encontrar ocupación en la isla. ${ }^{15}$

La extensión del bandolerismo en los campos en estos años, constituía también un reflejo de la situación económica y demostraba así mismo la existencia de una masa de desclasados del sistema productivo que encontraron como válvula de escape la violencia.

Aunque en la segunda mitad del siglo XIx, las autoridades y los hacendados en varias ocasiones se refieren a un "bandolerismo negro", sólo encontramos la partida del pardo Filomeno Sarduy, que apareció entre mayo y junio de 1881, quemando cańaverales y robando por la zona de Palmira, en Las Villas. Estaba compuesta por dieciséis hombres, de los cuales doce eran patrocinados, tres pardos libres y un blanco. Las autoridades españolas le atribuían "móviles políticos", pero en realidad no es un hecho comprobado, y pudiera responder a la intención de desprestigiar el movimiento independentista. Sarduy mantuvo en jaque a las fuerzas encargadas del orden hasta diciembre del propio año en que la gavilla fue desarticulada en un encuentro con la Guardia Civil. Algunos de sus integrantes obtuvieron el indulto, pero se les cambió el patronazgo y la jurisdicción de residencia, otros fueron enviados a la correccional de Isla de Pinos y a los más connotados -incluido el propio jefe-se les deportó, terminando la efímera vida de esta cuadrilla de patrocinadosbandoleros. ${ }^{16}$

Y en 1885, apareció la banda del pardo José Álvarez Arteaga, Matagás, integrada por treinta personas aproximadamente, de los cuales ocho eran blancos y el resto negros y mulatos. Y aunque es

\footnotetext{
${ }^{15}$ Véanse La Discusión, La Habana, 12 de octubre de 1886 y La Lucha, La Habana, 2 de octubre de 1886. Posiblemente la inmigración al Canal estuviese constituida fundamentalmente por jornaleros negros, la Revista de Agricultura reproducía una noticia de Las Novedades editado en Nueva York donde se recomendaba que fueran sólo personas de color dadas las duras condiciones de trabajo, véase Revista de Agricultura, núm. 4, La Habana, abril de 1886, 83. También Enrique Edo y Llop, Memoria histórica de Cienfuegos y su jurisdicción, 3ra. edición, La Habana, 1943, 267.

${ }^{16}$ Los datos sobre la partida de Filomeno Sarduy fueron tomados de la obra de Manuel de Paz Sánchez, José Fernández Fernández y Nelson López Novegil, El bandolerismo en Cuba. Presencia canaria y protesta rural, tomo 1, La Laguna, Tenerife, Centro de Cultura Popular Canaria, 1993-94, 120-124.
} 
anterior a la abolición de la esclavitud, en la documentación no se hace referencia al estatus de estos hombres por lo que es imposible determinar si eran libres - a diferencia de la antes mencionada-, siervos prófugos de las fincas, o expatrocinados que no encontraban trabajo y que por esta razón -u otras circunstancias- se convirtieron en bandidos. ${ }^{17}$

Es importante apuntar, que durante el periodo sólo se conocieron estas dos partidas de bandoleros integradas por negros y mulatos, lo cual no excluye que en el resto de las bandas existiesen "elementos de color". La mayoría de los bandidos eran hombres blancos, lo que desmiente los criterios establecidos en la época $-\mathrm{y}$ repetidos más tarde- de que la generalidad eran antiguos esclavos que tras la abolición escogieron ese camino para no trabajar.

Es cierto que los años ochenta se caracterizaron por el incremento de las actividades de los bandoleros, hasta convertirse en una de las manifestaciones de descontento más importantes en el periodo. Pero las causas de su incremento, habría que situarlas en las condiciones socioeconómicas de la isla. La actuación de las partidas coincidía con las provincias donde el proceso de concentración de la industria azucarera había sido más violento -La Habana, Matanzas y Santa Clara- aunque también podía ser coyunturalmente intensa en los lugares en donde por determinadas circunstancias era difícil la supervivencia para los trabajadores. Precisamente a partir de 1885 , creció de forma alarmante el número de partidas y de bandoleros; coincidiendo además con los movimientos huelguísticos de los obreros en las ciudades. ${ }^{18}$

${ }^{17}$ Ibid., pp. 154-155.

${ }^{18}$ En la segunda mitad de la década del ochenta coincidiendo con la profundización de la crisis económica y política de la isla hubo un renacer del bandolerismo, que llegó a convertirse en la fuente de agitación rural más importante del periodo. A partir de 1885 , comienzan a tomar renombre bandoleros como José Desiderio Matos (a) El Tuerto Matos, Manuel Romero Guzmán (a) Lengue Romero, e inicia su carrera en solitario el más carismático de los bandidos cubanos Manuel García Ponce, el Rey de los Campos de Cuba. Para mayor información sobre el bandolerismo en esta etapa véase además Imilcy Balboa, La protesta rural en Cuba. Resistencia cotidiana, bandolerismo y revolución (1878-1902), Madrid, CSIC, 2003 y Louis A. Pérez, Lords of de mountain. Social banditry and peasant protest in Cuba, 1878-1918, Pittsburgh, University of Pittsburgh Press, 1989. Sobre la situación de los trabajadores en las áreas urbanas, Joan Casa- 
¿Cómo conciliar entonces el fenómeno de la vagancia con el desempleo y la falta de ofertas de trabajo durante el tiempo muerto?

Según José A. Piqueras y Enric Sebastiá, el concepto de vago adquiere dimensión jurídica sobre todo en los periodos de crisis o de transición. ${ }^{19}$ En el caso cubano, y de forma particular en las circunstancias del tránsito del trabajo esclavo al trabajo libre, su aplicación debió cumplir un doble objetivo: por un lado a obligar a los trabajadores a someterse a la disciplina impuesta por el capital, y del otro a evitar el éxodo a las ciudades. Los hacendados estaban tratando de limitar el movimiento de los trabajadores para de esta forma asegurarse en su territorio mano de obra disponible. Las disposiciones contra la vagancia, no eran reflejo de un supuesto "mal social", sino que estuvieron encaminadas a reconducir a los marginados del proceso productivo y desarraigados en vías de proletarización y forzar su aceptación de las leyes laborales del capital.

En estas condiciones no se justificaban las disposiciones legales acerca de la vagancia, cuando además en España se había dejado de considerar como un delito. Ante el creciente temor en la isla por el aparente aumento de la vagancia, las autoridades peninsulares, por Real Orden de 5 de junio de 1881, ordenaron la formación de un expediente para estudiar el asunto. Una nueva Real Orden dictada en 1884, señalaba que en realidad no había prisa por responder. No fue hasta 1889, ocho años después, que se completó el informe. Habían transcurrido poco más de dos años desde que se proclamara la abolición de la esclavitud y las conclusiones del estudio venían a demostrar el verdadero interés de los dueńos de ingenios: controlar la población superflua que escapaba a las nuevas reglas del mercado laboral. Mientras que las autoridades aprovecharon la coyuntura para juzgar a los bandoleros por el delito de vagancia.

novas Codina, Bread or bullets. Urban labor and spanish colonialism in Cuba.1850-1898, Pittsburg, University of Pittsburg Press, 1998. Sobre el proceso de concentración de la industria azucarera, Fe Iglesias, Del Ingenio al Central, San Juan, Editorial de la Universidad de Puerto Rico, 1998.

${ }^{19}$ José Antonio Piqueras y Enric Sebastiá, Agiotistas, negreros y partisanos. Dialéctica social en vísperas de la Revolución Gloriosa, Valencia, Edicions Alfons el Magnànim, 1991, 330-338. 
No por casualidad las medidas propuestas resultaban sospechosamente similares a las estipuladas en el Reglamento de 1880: los "vagos" quedaban obligados a trabajar por contrata en los ingenios durante dos años.

El supuesto problema de la vagancia sirvió además para justificar la entrada de inmigrantes - petición recurrente desde que se inició el proceso de abolición-. Había que importar trabajadores pues los nativos eran poco dados al trabajo y aficionados al bandolerismo. Si a lo largo del siglo todos habían convenido en la falta de aptitud de los europeos para los trabajos agrícolas, en la segunda mitad de la década del ochenta, se les colocó incluso por encima de los jornaleros de la isla: "hay que convenir que el amor al trabajo no es fruto muy espontáneo en estos climas; y que sólo la emigración de trabajadores puede salvar a la agricultura cubana de la suerte que ha cabido a esa principal fuente de producción en casi todas las demás Antillas" ${ }^{20}$

De lo que se trataba era de contar con un mayor número de trabajadores y saturar el mercado para provocar la caída de los jornales. Los trabajadores que no aceptasen las condiciones impuestas y emigrasen a las ciudades, donde también había un fuerte desempleo, podían terminar deambulando por las calles y deportados al correccional establecido en la antigua Isla de Pinos para acoger a los vagos y bandoleros.

\section{ViVir EN LA PLANTACión. Los LÍMITES DE LA LIBERTAD}

En el caso de Cuba, estudiar la incorporación de los antiguos patrocinados al mercado de trabajo libre se dificulta pues con posterioridad a la abolición en los censos y padrones se suprimieron las indicaciones sobre el estatus o algún otro elemento distintivo. Pero podemos inferir que a pesar de las aprensiones de los hacendados sobre las consecuencias que el fin del sistema esclavista y por ende el cambio en la condición jurídica de los trabajadores traería sobre la

${ }^{20}$ Fragmento de artículo de La Voz de Cuba, periódico afín al Partido Unión Constitucional, reproducido por La Libertad, que había sido el vocero del Partido Liberal Democrático entre 1878 y 1879. La Habana, 31 de julio de 1885. 
disponibilidad de la mano de obra, y de los recelos del gobierno sobre la extensión del bandolerismo, con posterioridad al 7 de octubre apenas se produjeron cambios reales en la vida de los patrocinados y el tan temido traslado de estos elementos del campo a las ciudades no fue inmediato ni masivo.

En este resultado influyeron tanto factores objetivos -las medidas implementadas por el gobierno y los hacendados- como subjetivos. Y en este sentido habría que considerar en primer lugar, las relaciones de dependencia o afectivas, tanto en sentido vertical -con los amos- como horizontal -la familia- ${ }^{21}$ lo que determinó que muchos prefirieran quedarse para estar más cerca de sus familiares. En segundo lugar, no podemos olvidar el elemento de independencia y a la vez de sujeción que significaron los conucos: una porción de terreno que recibían los esclavos para el autoabastecimiento, lo que debió resultar un aliciente nada despreciable, que al tiempo que los ataba a la hacienda les otorgaba cierta autonomía a la hora de la alimentación y comercialización de lo cultivado. Para estos hombres y mujeres, cuyas vidas y las de sus antecesores habían transcurrido en una hacienda azucarera, es poco probable que su mentalidad cambiase tan rápidamente y se aventuraran sin más a marcharse a los centros urbanos a probar fortuna.

La incidencia de los factores subjetivos en la permanencia de los antiguos esclavos en las haciendas es un elemento que apenas ha sido destacado por la historiografía, donde ha primado la tesis -que reproduce los temores de los dueños de ingenios- acerca de la movilidad tras la abolición. ${ }^{22}$ Pero como hemos visto, este desplazamien-

${ }^{21}$ La tesis de los alineamientos verticales y horizontales, ha sido planteada por Hamza Alavi, en su estudio de lo que denomina "las lealtades primordiales", aunque su análisis se refiere al campesinado, también pueden ser aplicado a las relaciones esclavo-amo-familia. Véase Eric Hobsbawm y Hamza Alavi, Los campesinos y la política. Las clases campesinas y las lealtades primordiales, Barcelona, Anagrama, 1976, 116.

${ }^{22}$ Maluquer de Motes afirma que la abolición trajo consigo el abandono de las explotaciones azucareras por el traslado de los antiguos patrocinados a La Habana, otras áreas urbanas o la región oriental donde se estaban repartiendo terrenos. Rebecca Scott adelanta una interrogante al analizar la movilidad de los trabajadores y los cambios en la composición racial de la fuerza de trabajo en los ingenios Mapos, San Fernando y el distrito de Lajas. Mientras Ada Ferrer desarrolla esta tesis y concluye que hubo un fuerte movimiento de los esclavos liberados hacia el este del país, en particular a las áreas 
to fue limitado, y en todo caso posterior. Su origen más que en la actitud de los esclavos vendría determinado por la falta de disposición de los amos para negociar nuevas condiciones de trabajo. ${ }^{23}$

Dos meses antes de que fuese abolida formalmente la esclavitud, la Junta de Agricultura, Industria y Comercio de la Habana reconocía que "casi la totalidad" de los trabajadores de los ingenios eran los mismos integrantes de las antiguas dotaciones. Y explicaba a continuación: "por lo poco aficionados que son a cambiar de lugar y más que nada, porque a pesar de los malos presagios que algunos hacían para cuando estos infelices hubieran sido declarados libres, la mayoría de ellos está dedicada al trabajo". ${ }^{24}$ Tales criterios venían avalados además por la situación de las dotaciones que en la zafra de 1884 habían trabajado sólo por la alimentación, en aquellas fincas donde los propietarios, ante los bajos precios del azúcar, habían planteado el despido como alternativa.

Para la Real Sociedad Económica de Amigos del País no había dudas, los últimos patrocinados que se incorporaban al mercado laboral en 1886 harían igual que "los otros 170 mil que les precedieron en el goce de la libertad: trabajar en los campos; sin lo cual no hubiera sido posible preparar y realizar la enorme zafra de casi un millón de bocoyes de azúcar que se han elaborado este año". ${ }^{25}$

más afectadas por la guerra, donde se promovieron los asentamientos a tenor del proceso de reconstrucción. Véanse Jordi Maluquer de Motes, Nación e inmigración. Los españoles en Cuba (ss XIX y XX), Gijón, Júcar, 1992, 47; Rebecca Scott, La emancipación de los esclavos en Cuba. La transición al trabajo libre, 1860-1899, México, Fondo de Cultura Económica, 1989, 244-248; Ada Ferrer, To make a free nation: race and the struggle for independence in Cuba (1868-1898), tesis de doctorado, Michigan, University of Michigan, 1995, 199.

${ }^{23}$ Hebe María Matos en su estudio sobre la extinción de la esclavitud en Río de Janeiro, destaca cómo los dueños "confiaron" en la fuerza de los lazos sociales de familia y vecindad creados durante la esclavitud para mantenerlos, sino ya en sus haciendas, al menos en la región. Y de hecho, sólo alrededor de 10 por ciento de los libertos abandonó las fincas de forma inmediata. Hebe María Mattos de Castro, "El color inexistente. Relaciones raciales y trabajo rural en Río de Janeiro tras la abolición de la esclavitud", Historia Social, núm. 22, Valencia, 1995, 83-100.

24 "Informe de la Junta Provincial de Agricultura y Comercio de La Habana", 7 de agosto de 1886, AHN, Ultramar Fomento, Leg. 280, núm. 2.

25 "Informe de la Real Sociedad Económica de Amigos del País de La Habana", 21 de agosto de 1886, AHN, Ultramar, Fomento, Leg. 280, núm. 2. 
En todo caso, la conjunción de ambos factores - los lazos de parentesco y los conucos de un lado y las medidas de coerción por el otrocumplieron su cometido. Y así lo atestiguan los informes remitidos al gobierno de la isla por los diferentes gobernadores provinciales en respuesta a la circular remitida varios meses después de la abolición, el 5 de marzo de 1887, por la que se pedía que reseñaran el estado en que se encontraba la contratación del trabajo por los libertos. ${ }^{26}$

De la información aportada en cada una de las zonas, se puede observar que aunque existían pequeñas diferencias regionales, la tendencia general apuntaba hacia la dedicación al trabajo de los antiguos siervos. Desde La Habana y Santa Clara, se informaba que en la primera éstos individuos mostraban una "completa sumisión a los preceptos de la ley y regular aplicación al trabajo”, mientras que en la segunda se aseguraban que "laboraban ordinariamente".

En Matanzas, con el más alto número de emancipados, también se indicaba que los libertos en su mayor parte habían permanecido en el campo, aunque se podía observar cierta movilidad, aunque interna "dentro de los términos municipales". Según se consignaba en el informe del gobernador provincial al capitán general una parte se quedó con sus expatronos, otros cambiaron de finca en busca de mejores jornales y un tercer grupo se movió por el territorio en cuadrillas. Las dificultades se concentraron en torno al requisito de acreditar que poseían una ocupación fija. No sólo por la particular organización del trabajo en la región, a través de las cuadrillas - tal vez promovidas por los propios hacendados pues ya habían dado resultado con los asiáticos-. También por la actitud de muchos dueños que no permitían que sus trabajadores se ausentaran para ir a justificar su estatus.

Mientras en Puerto Príncipe y Pinar del Río, con un porcentaje mucho menor de esclavos en el periodo anterior, dadas las características económicas de esas zonas - ganadería en la primera y el tabaco en la segunda- las autoridades se quejaban del incumplimiento de este trámite, aunque admitían que por lo demás no confrontaban problemas.

26 "Consulta del Gobernador de La Habana sobre libertos que por no acreditar que trabajasen son destinados a obras públicas”, ANC, ME, Leg. 3640, exp. Bq. (la información que se relaciona a continuación está tomada del mismo documento). 
En Santiago de Cuba, sí observamos una situación diferente al resto de la isla. La mayoría de los libertos se dedicaron como arrendatarios al fomento de pequeñas estancias, vegas o cafetales. Esta particularidad tenía su origen en los repartos de terrenos efectuados en la región oriental a tenor del Real Decreto de 27 de octubre de 1877. Aproximadamente 66 por ciento de los lotes entregados correspondió a personas de color. Aun cuando en principio los repartos estuvieron marcados por las prevenciones políticas, pues al tiempo que se intentaba premiar a los que habían combatido en las filas del Ejército español se trató de frenar la agitación política existente en el territorio, el incremento del número de lotes entregados a partir de 1882, pudiera ser indicativo de que muchos libertos aprovecharon esta vía para convertirse en propietarios. ${ }^{27}$

En dicha provincia, además, las autoridades consideraban contraproducente imponer obligaciones de cualquier índole a estos hombres, pues lo podrían interpretar como una amenaza a la libertad, y dado el espíritu separatista que caracterizaba al territorio la medida podría generar disturbios políticos. ${ }^{28}$ En definitiva, según el propio negociado de Orden Público y Policía se pudo comprobar que:

el espíritu que predomina en la generalidad de los individuos que acaban de salir del patronato es el de la mayor sumisión a los preceptos de la ley, y el de una regular aplicación al trabajo si bien en algunos términos municipales han dejado los interesados de cumplir el requisito de justificar periódicamente ante la autoridad local el hecho de la contratación de sus servicios,

${ }^{27}$ El Real Decreto de 27 de octubre de 1877, establecía el reparto de terrenos públicos: baldíos y realengos o de propios y arbitrios. Tendrían derecho a solicitarlos los licenciados del Ejército y voluntarios movilizados o que hubiesen asistido en alguna función de guerra, vecinos que permanecieron fieles al gobierno y sufrieron pérdidas considerables a causa del conflicto e individuos presentados a indulto. Para mayor información sobre la política de reparto de terrenos, sus resultados finales y su vinculación con el azúcar en la isla, véase Imilcy Balboa, Los brazos necesarios. Inmigración, colonización y trabajo libre en Cuba 1878-1898, Valencia, Centro Francisco Tomás y Valiente unED Alzira-Valencia, Fundación Instituto de Historia Social, 2000, 49-118.

${ }^{28}$ En la zona oriental habían comenzado las dos contiendas independentistas. La Guerra de los Diez Años o Guerra Grande (1868-1878) y la Guerra Chiquita (1879). Al respecto véase Diana Abad; María del Carmen Barcia y Óscar Loyola, Historia de Cuba II. La Guerra de los Diez Años, La Tregua Fecunda, La Habana, Ed. ENPES, 1989. 
aunque no consta que ninguno haya abandonado su antiguo género de vida, omisión acaso que no reconozca por origen otra causa que la ignorancia propia de la clase que se viene haciendo mención. ${ }^{29}$

Todo parece indicar que el éxodo a las ciudades, cuando se dio, más bien constituyó un proceso lento determinado por la condición gradual de la abolición y la propia mentalidad de los antiguos siervos, sin olvidar la disposiciones gubernamentales que los obligaban a mantener el vínculo laboral y los diversos mecanismos de sujeción ensayados por los dueños. Si desde 1880 los que obtenían su libertad se hubiesen marchado a las ciudades, la industria azucarera no hubiera podido sobrevivir, y en estos años la producción del dulce no se resintió e incluso creció en algunos años. Las afectaciones a este sector se produjeron más bien por coyunturas exteriores vinculadas a los precios del mercado mundial.

Cuadro 1. Producción de azúcar entre 1880-1886

\begin{tabular}{cc}
\hline Años & Producción de azúcar (en @) \\
\hline 1880 & 618,654 \\
1881 & 580,894 \\
1882 & 620,565 \\
1883 & 601,426 \\
1884 & 626,477 \\
1885 & 628,990 \\
1886 & 657,290 \\
Total & $4,334,296$ \\
\hline
\end{tabular}

Fuente: Manuel Moreno Fraginals, El ingenio. Complejo económico social cubano del azúcar, tomo 3, La Habana, Ciencias Sociales, 1978, 37.

${ }^{29}$ Dictamen del Negociado de Orden Público y Policía en "Consulta del Gobernador de La Habana sobre libertos que por no acreditar que trabajasen son destinados a obras públicas”, ANC, ME, Leg. 3640, exp. Bq. (El subrayado es de la autora). 
En el caso de las mujeres, sí podemos apreciar cierta tendencia a establecerse en los pueblos y ciudades, pero no podemos catalogarlo como algo generalizado, más bien fue un fenómeno que se dio sobre todo en el occidente: Matanzas y algunas localidades de Pinar del Río. Las que no permanecieron directamente en la agricultura, se dedicaron a las faenas domésticas, el cuidado de los niños cuyos padres trabajaban en el campo, al lavado de ropa, planchado, costura u otros servicios. Aunque en tiempos de zafra cuando aumentaban los salarios algunas solían regresar a trabajar en dicha actividad. Mientras:

Los hombres son los que por regla general, continúan dedicados al cultivo de los campos permaneciendo las mujeres en los poblados, ocupadas en los quehaceres propios de su sexo y de su nueva condición social: aquellos como es lógico que suceda, prefieren prestar sus servicios en las fincas cercanas por salario menor que el que se le ofrece en las más apartadas. Así se explica la diferencia del valor de los jornales en las distintas comarcas de esta Isla. ${ }^{30}$

El análisis de la evolución de la población negra en las zonas azucareras hasta 1887 -pues en las estadísticas de la década del noventa no aparecían reflejados- podría arrojar luz sobre tal problemática. Si consideramos toda la población negra como el elemento fundamental en la composición de la mano de obra -ya fuese libre, emancipada o esclava- podemos inferir que las disminuciones fueron mínimas excepto en Santiago de Cuba, donde se observa una deducción mayor que podría estar relacionada con la participación de los sectores negros y mulatos en la Guerra de los Diez Años y la Guerra Chiquita, y cierta recuperación en la década del ochenta, que pudo tener su origen en dos acontecimientos: a) el establecimiento de ingenios centrales en la región y b) el proceso de reparto de terrenos tras la guerra de 1868. El primero, ofrecía nuevas oportunidades de empleo en la agricultura, y el segundo debió constituir un atractivo nada despreciable.

Mientras en el caso de la región matancera-Cárdenas, Colón y Matanzas- y las localidades del centro -Cienfuegos, Remedios y

30 "Consulta del Gobernador de La Habana sobre libertos que por no acreditar que trabajasen son destinados a obras públicas”, ANC, ME, Leg. 3640, exp. Bq. 
Sagua la Grande-, donde la industria azucarera estaba en expansión el aumento de la población de color fue más marcado. De ahí quizás el trasvase de población de La Habana hacia las nuevas zonas con mayores posibilidades económicas. ${ }^{31}$

CuAdro 2. Evolución de la población negra en las zonas azucareras. 1862-1887

\begin{tabular}{lrrr}
\hline Provincias & 1862 & 1877 & 1887 \\
\hline Pinar del Río & 6,933 & 5,723 & 5,655 \\
La Habana & 64,041 & 56,292 & 50,839 \\
Matanzas & 90,654 & 94,789 & 105,448 \\
Santa Clara & 60,721 & 60,014 & 73,797 \\
Oriente & 81,715 & 56,576 & 68,198 \\
\hline
\end{tabular}

Sólo contabilizamos en cada provincia las jurisdicciones donde el cultivo del azúcar era la actividad fundamental. En el caso de Pinar del Río (la jurisdicción de Bahía Honda); en La Habana (Guanajay, Güines y Jaruco); en Matanzas (Cárdenas, Colón y Matanzas); Las Villas (Cienfuegos, Remedios y Sagua La Grande) y en Oriente (Santiago de Cuba y Guantánamo) Puerto Príncipe no se incluye por ser una zona ganadera, con menor presencia de la esclavitud.

Fuente: Cuadro estadístico de la isla de Cuba en 1862, La Habana, Imprenta del Gobierno y Capitanía General, 1863. Censos de 1877 y 1887 en CEE, Los censos de población y vivienda en Cuba, tomo I, vol. 2 (información cedida por la Dra. Gloria García).

En general, tras la abolición la situación de los expatrocinados apenas sufrió variación, con excepción de la relativa movilidad y alguna que otra modificación en las condiciones de vida. Los que laboraban en los centrales continuaron viviendo en los antiguos barracones con la salvedad de que ahora no tenían cerrojos y se les permitió abrir agujeros en las paredes, que fungían como ventanas. Aunque hubo haciendas que mantuvieron reglamentación y control nocturno y a la vieja usanza esclavista encerraban a los trabajadores

${ }^{31}$ Estas cifras no agotan la cuestión desde el punto de vista cuantitativo pues no puede estimarse el potencial laboral sin tener en cuenta variables como la edad o la diferenciación regional. Además se deberían considerar también otros aspectos, como la posibilidad de desviación de ese potencial hacia la economía informal o la mendicidad antes que emplearse en el corte de caña, y las inclinaciones socioculturales asociadas a la existencia de la esclavitud y sus secuelas en el comportamiento social y económico. 
bajo llave durante la noche. En cuanto a la jornada laboral Enrique Cresi, en un artículo aparecido en El Productor en 1890, nos ofrece el siguiente testimonio: "A las cuatro de la mañana comienza la faena en los ingenios. El mayoral les abre el barracón. A las once una campana anuncia el almuerzo. A las doce vuelve a empezar el trabajo hasta las seis en invierno, o hasta las siete en verano. De trece a catorce horas de trabajo incesante y penoso". ${ }^{32}$

La alimentación que recibían también fue análoga a la que tomaban los esclavos con anterioridad (arroz, frijoles, harina, tasajo y viandas), pero a diferencia del periodo anterior los costes se trasladaban a los trabajadores. Así, cuando era suministrada por los dueños su importe se deducía del salario.

En cuanto al pago de jornales, no existían sueldos fijos, éstos variaban en dependencia del lugar y de la mayor o menor demanda de fuerza de trabajo. ${ }^{33}$ Por demás, los productos necesarios debían adquirirlos en la tienda más cercana que por lo general también pertenecía al dueño del central o de la colonia, a través de vales o fichas que sólo eran canjeables en la propia tienda. Por lo general, el trabajador terminaba la zafra endeudado con la tienda y al ańo siguiente debía contratarse con el mismo dueño para satisfacer los pagos atrasados, lo que los mantenían atados al propietario de la finca, viviendo encerrados en un círculo vicioso. ${ }^{34}$

Lejos de los centros poblacionales, con su capacidad de movimiento limitada, aislados en los predios rurales y tras agotadoras

${ }^{32}$ El Productor, La Habana, 24 de enero de 1890, citado por Olga Cabrera en "Enrique Cresi: un patriota obrero", Revista Santiago, núm. 36, diciembre de 1979, 131-132.

${ }^{33}$ Por ejemplo en 1888, en la jurisdicción de Cienfuegos se pagaba de 14 a 17 pesos oro mensuales más la alimentación y en Sagua la Grande de 12 a 14 pesos oro, sin embargo, en Matanzas -donde el número de trabajadores era superior- los jornales oscilaban entre 35 y 40 en billetes de banco (lo que prácticamente los reducía a la mitad) sin la comida. Para 1890, en Pinar del río se pagaban 35 pesos en billetes de banco, en La Habana, Matanzas y parte de Santa Clara 40 pesos, en Puerto Príncipe y Santiago de Cuba 22 pesos. Véanse Revista de agricultura, La Habana, año II, núm. 46, 565-567 y Revista de Agricultura, La Habana, ańo viII, núm. 23, 279.

34 "Los vales se extendieron rápidamente. Los ingenios que menos cantidad habían emitido estaban en el rango de los 6 mil pesos, otros habían puesto en circulación hasta 17 mil pesos, y en el país llegaron a circular unos 4 millones de pesos por este concepto". Comunicación del Alcalde Municipal de Güira al Gobernador Provincial, 1886, ANC, ME, Leg. 4330, exp. Ab. 
jornadas de trabajo, los que laboraban en los campos no se vincularon a las luchas políticas y sociales de los sectores negros y mulatos de las áreas urbanas. Aunque también es necesario aclarar que estos últimos tampoco se mostraron muy proclives a defender a los que habitaban en los campos.

La única agrupación de corte cívico-político de este sector, El Directorio Central de las Sociedades de la Raza de Color ${ }^{35}$-fundado el 20 de septiembre de 1888- fue la única agrupación que trató de defender los derechos de los negros y mulatos. Sus reivindicaciones, acordes con su objetivo: lograr la igualdad social y política, se concentraron en lograr que la escuela municipal fuese común para los niños de todas las razas, obtener que "los hombres de color" fuesen admitidos en los establecimientos públicos y eliminar las diferencias en las cédulas personales. Asuntos sin duda importantes, pero que soslayaban las demandas laborales y olvidaban al sector agrario, precisamente donde se encontraban laborando la mayoría de los antiguos esclavos.

Para aquellos que continuaban laborando en los ingenios, las reclamaciones laborales ocupaban un primer lugar. Su realidad inmediata estaba más ligada a la supervivencia diaria, trabajar para obtener el dinero necesario con que mantenerse a sí o a su familia, en el caso de que la tuviese, sobre todo durante el tiempo muerto en que las opciones se reducían prácticamente a cero. Sobrevivir en una sociedad excluyente y racista, no resultó fácil para la gran masa de negros recién liberados y en particular para los trabajadores rurales. Cuatro siglos de mayorales y látigos, que habían hecho del trabajo del campo "un trabajo de negros", no se borraban del imaginario colectivo con un decreto. Y aunque se establecía en la ley de 1880 que al cabo del tiempo prescrito los libertos gozarían de todos sus "derechos civiles y políticos", la realidad fue bien diferente.

En una exposición presentada al gobernador general en 1892, el Directorio expresaba a propósito de la situación real de los antiguos esclavos:

${ }^{35}$ Para más información sobre el Directorio en Oilda Hevia Lanier, El Directorio Central de las sociedades negras en Cuba, La Habana, Ciencias Sociales, 1996. 
Mantiénesele, como antes, en el propio estado de inferioridad, niégasele toda consideración social, trátasele con desdén por los agentes subalternos del poder, aléjasele con deplorable desconfianza de la vida política, y con negligencia que el respeto tan solo impide calificar de deliberada, se dejan sin efecto en la práctica hasta las resoluciones gubernativas que resguardan su decoro y amparan su derecho a la vida social. ${ }^{36}$

No sólo se les mantuvo en un lugar subalterno desde el punto de vista económico, sino que también en el nivel político se les cerró la posibilidad de lograr una mejoría social. Los requisitos electorales vigentes, reducían al mínimo las probabilidades de estos hombres de formar parte de la masa de votantes. Aun cuando la ley electoral de 1891 no establecía distinciones de raza -innecesarias en las nuevas condiciones- sí era restrictiva desde el punto de vista económico, pues instituía el pago de diez pesos para todos los electores, y consideraba parte de la masa electoral a los que pagaran cinco pesos por contribución de inmuebles, cultivo, ganadería o subsidio industrial. Cifras aparentemente bajas, pero difíciles de cumplimentar en la práctica, sobre todo para aquellos que tras la abolición laboraban como jornaleros en las fincas. ${ }^{37}$

A lo anterior habría que añadir la situación de la isla. Para 1894, el desempleo se había convertido en algo alarmante no sólo en el sector agrícola sino también en los centros urbanos, que además recibían a los trabajadores rurales que no hallaban colocación en los campos. Los anarquistas, en un Manifiesto destinado a los trabajadores de la isla, describían esta situación: "Diariamente llegan a la ciudad, procedentes del campo, tribus numerosas de honrados trabajadores a quienes hacendados sin conciencia, echan a la calle sin pagarles sus escasísimos jornales" ${ }^{38}$

La zafra de 1894-1895 comenzó en condiciones difíciles, la caída de los precios del dulce y la incertidumbre en torno a su comer-

${ }^{36}$ La Igualdad, La Habana, 7 de diciembre de 1892.

${ }^{37}$ Véase Ley provisional de la Isla de Cuba, La Habana, Imprenta del Gobierno y Capitanía General, 1890, 24.

38 "Manifiesto de los anarquistas a los trabajadores de la Isla de Cuba", ANC, AH, Leg. 106, núm. 269. 
cialización determinó que en varias zonas los hacendados, ante la falta de liquidez, optaran por economizar los brazos y los jornales. Los trabajadores emigraban de una región a otra en busca de trabajo y muchas haciendas ofrecían ocupación sólo a cambio de la manutención.

Si consideramos que en los momentos de la abolición -1886-el mayor porcentaje de la fuerza laboral correspondía a los negros y mulatos, y que la generalidad de ellos continuó dedicado a la agricultura tras la supresión del patronato, este sector -el más numeroso dentro del contingente de trabajadores agrícolas-, debió resultar uno de los más afectados por esta situación. Así, cuando en 1895 estalló una nueva guerra por la independencia, los sectores negros y mulatos se incorporaron de forma mayoritaria a las filas del Ejército Libertador en busca de una libertad verdadera. ${ }^{39}$ Aunque la historia que sigue, con el fin del colonialismo español y el establecimiento de la República en 1902, terminaría por frustrar nuevamente sus aspiraciones.

\section{Conclusiones}

La liberalización del mercado de trabajo con el fin de la esclavitud y la expansión de las relaciones capitalistas en el agricultura se produjeron en una coyuntura difícil para los dueños de esclavos ya que su conversión en burgueses llegaba acompañada de un desplome de los precios del azúcar y la reorganización de los mercados en el nivel internacional. La estrategia de los dueños de ingenios se centró entonces en hacer más rentable la industria y dentro de ella el problema laboral jugaría un papel definitorio.

${ }^{39}$ Sobre al participación de los negros en la contienda de 1895 y su situación en los primeros ańos de la República véanse Óilda Hevia, "1895-1898: ¿ Guerra racista o demagogia?”, Debates Americanos, núms. 5-6, enero diciembre, 1998, 35-45. Aline Helg, Lo que nos corresponde. La lucha de los negros y mulatos por la igualdad en Cuba. 1886-1912, La Habana, Imagen Contemporánea, 2000 y Alejandro de la Fuente, $A$ nation for all. Race, inecuality, and politics in twentieth-century Cuba, Chapel Hill y Londres, The University of North Carolina Press, 1999. 
Los dueños de ingenios temían lo que pasaría tras la abolición con la disponibilidad de brazos y lograron con el Decreto de Abolición de 1880, varios ańos para prepararse. El hecho de que se declararan partidarios de la abolición total aun antes del plazo establecido legalmente, no respondía a filantropías de última hora, durante el Patronato, se ensayaron -con éxito- los mecanismos de sujeción que permitirían el control del mercado laboral tras la supresión definitiva del sistema.

La liberalización del mercado laboral comportó el establecimiento de un nuevo tipo de relaciones entre los dueños y los trabajadores, de manera que los segundos se integraran en la lógica de las relaciones capitalistas. Y para sujetar los trabajadores a los ingenios apelaron a la reglamentación del trabajo sazonado con alusiones a la vagancia y la supuesta existencia de un "bandolerismo negro".

Los patrocinados, ahora libres, debían demostrar que tenían un oficio u ocupación fijos o serían catalogados de vagos. Las leyes contra la vagancia tenían un doble objetivo: por un lado, obligar a los trabajadores a someterse a la disciplina impuesta por el capital y, del otro, evitar el éxodo a las ciudades. Los hacendados estaban tratando de limitar el movimiento de los trabajadores para de esta forma asegurarse en su territorio mano de obra disponible. Por otra parte, la persecución del bandolerismo les permitiría el control de los que no aceptasen las condiciones de trabajo y quedaran al margen de las reglas del sistema.

Los mecanismos de sujeción funcionaron con éxito. Con posterioridad a 1886 apenas se observan cambios en la vida de los antiguos patrocinados, que continuaron laborando en los ingenios de manera ordinaria. El pago en vales o fichas, vendría a cerrar el círculo de control, transformando los salarios en una vía de intervención y regulación de la disciplina laboral.

La ley de 1880 establecía que la libertad vendría acompańada del goce de los derechos civiles para los antiguos esclavos, pero, en realidad, continuaron ocupando un lugar subalterno, tanto desde el punto de vista económico, como político, y se les negó la posibilidad de lograr una mejoría social. 
MAPA. División por departamentos y provincias

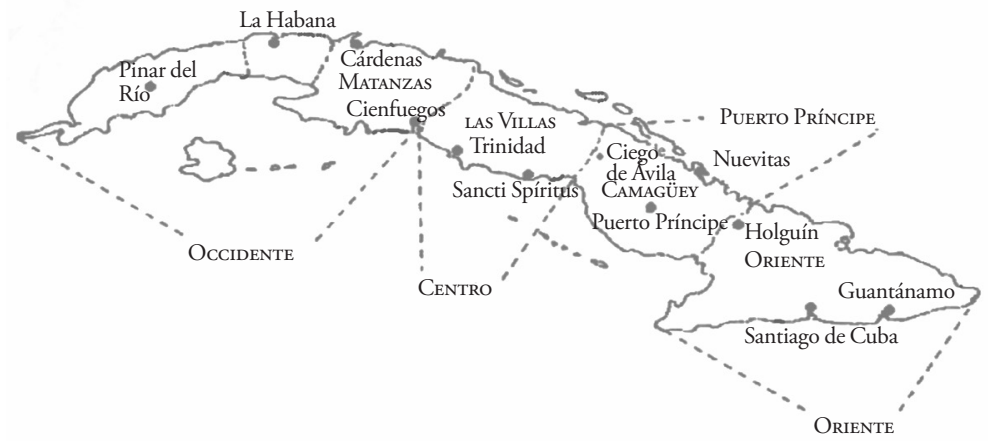

Nota: Para una mejor comprensión y unificación del texto se mantienen los cuatro Departamentos y la división por provincias de1878.

\section{BiBLIOGRAFÍA}

BALBOA, Imilcy, Los brazos necesarios. Inmigración, colonización y trabajo libre en Cuba, 1878-1898, Valencia, Centro Francisco Tomás y Valiente unED Alzira-Valencia, Fundación Instituto de Historia Social, 2000.

, La Protesta rural en Cuba. Resistencia cotidiana, bandolerismo y revolución (1878-1902), Madrid, csic, 2003.

"El camino a la libertad. Los patrocinados en las áreas rurales. Cuba 1878-1886”, Espace Caräibes Amériques, París, Université des Antilles-Guyane, 2000.

Barcia, María del Carmen, Burguesía esclavista y abolición, La Habana, Ciencias Sociales, 1987.

, "Los proyectos de población blanca y la Real Sociedad Económica de Amigos del País”, Espacies Caräibes, núm. 2, París, Université des Antilles et Guyane, 1994.

Barcia, María del Carmen, Mildred de la Torre, Gloria García, Imilcy Balboa y Raquel Vinat, La turbulencia del reposo. Cuba 1878-1895, La Habana, Ciencias Sociales, 1998.

Barnet, Miguel, Biografía de un cimarrón, Barcelona, Ariel, 1968. BERGAD, Laird W., Cuban Rural Society in the nineteenth century: the 
social and economic history of the monoculture in Matanzas, Princeton, Princeton University Press, 1990.

, "The economic viability of sugar production based on slave labour in Cuba, 1859-1878”, Latin American Research Review, núm. xxIv/1, 1989.

Bonilla, Raúl Cepero, Azúcar y Abolición, La Habana, Ciencias Sociales, 1978.

Casanovas Codina, Joan, Bread or bullets. Urban labor and spanish colonialism in Cuba.1850-1898, Pittsburg, University of Pittsburg Press, 1998.

Edo y Llop, Enrique: Memoria histórica de Cienfuegos y su jurisdicción, 3ra. edición, La Habana, 1943.

FERRER, Ada, To make a free nation: race and the struggle for independence in Cuba (1868-1898), Tesis de doctorado, Michigan, University of Michigan, 1995.

"Esclavitud, ciudadanía y los límites de la nacionalidad cubana: la guerra de los diez años, 1868-1878”, Historia Social, núm. 22, Valencia, 1995.

Fuente, Alejandro de la, A nation for all. Race, inecuality, and politics in twentieth-century Cuba, Chapel Hill y Londres, The University of North Carolina Press, 1999.

, "Negros y electores: desigualdad y políticas raciales en Cuba, 1900-1930", en Consuelo Naranjo, Miguel A. Puig Samper y Luis M. García, eds., La nación soñada: Cuba, Puerto Rico y Filipinas, ante el 98, Madrid, Doce Calles, 1996.

GARcía, Gloria, "El auge de la sociedad esclavista en Cuba," en Instituto de Historia de Cuba, Historia de Cuba. La Colonia, evolución socioeconómica y formación nacional. De los orígenes hasta 1867, tomo 1, cap. VI, La Habana Ed. Política, 1994.

- La esclavitud desde la esclavitud. La visión de los siervos, México, Centro de Investigación Científica "Ingeniero Jorge A. Tamayo", A.C., 1996.

, "Trabajadores urbanos: comportamiento político y conciencia de clase" en Carmen Barcia y otros, La turbulencia del reposo. Cuba 1878-1895, La Habana, Ciencias Sociales, 1998. , "La sociedad cubana a fines de siglo", en Manuel López, 
comp., La guerra de 1898, San José, FLACSO-SSRC, 1999.

Gómez, Juan Gualberto, La cuestión de Cuba en 1884, Madrid, Imp. de Aurelio J. Alaria, 1885.

HeLG, Aline, Lo que nos corresponde. La lucha de los negros y mulatos por la igualdad en Cuba. 1886-1912, La Habana, Imagen Contemporánea, 2000.

Hevia Lanier, Oilda, El Directorio Central de las sociedades negras en Cuba, La Habana, Ciencias Sociales, 1996.

Iglesias, Fe, Del Ingenio al Central, San Juan, Editorial de la Universidad de Puerto Rico, 1998.

, "Los contratados peninsulares a Cuba", Anuario de Estudios Americanos, núm. 2, tomo LI, Sevilla, 1994.

Instituto de Historia de Cuba, Historia de Cuba. La Colonia, evolución socioeconómica y formación nacional. De los orígenes hasta 1867, tomo 1, La Habana, Ed. Política, 1994.

- Historia de Cuba. Las luchas por la independencia nacional y las transformaciones estructurales. 1868-1898, tomo 2, La Habana, Ed. Política, 1996.

Le Riverend, Julio, Historia económica, La Habana, Instituto Cubano del Libro, 1971.

Maluquer de Motes, Jordi, Nación e inmigración. Los españoles en Cuba (ss XIX y XX), Gijón, Júcar, 1992.

Mattos de Castro, Hebe María, "El color inexistente. Relaciones raciales y trabajo rural en Río de Janeiro tras la abolición de la esclavitud", Historia Social, núm. 22, Valencia, 1995.

Moreno Fraginals, Manuel, El Ingenio. Complejo económico social cubano del azúcar, La Habana, Ciencias Sociales, 1978.

Naranjo, Consuelo y Armando García, Racismo e inmigración en Cuba en el siglo XIX, Madrid, Doce Calles, 1996.

y Tomás Mallo Gutiérrez, eds., Cuba la perla de las Antillas, Madrid, Doce Calles, 1994.

e Imilcy BALBOA, "Colonos asiáticos para una economía en expansión: Cuba, 1847-1880", Revista Mexicana del Caribe, núm. 8, Quintana Roo, 1999.

Navarro Azcue, Concepción, La abolición de la esclavitud negra en la legislación española. 1870-1886, Madrid, Instituto de Coope- 
ración Iberoamericana, Ediciones Cultura Hispánica, 1987.

OrTiz, Fernando, Los negros esclavos, La Habana, Ciencias Sociales, 1987.

Paz Sánchez, Manuel de, José Fernández Fernández y Nelson López Novegil, El bandolerismo en Cuba. Presencia canaria y protesta rural, La Laguna, Tenerife, Centro de Cultura Popular Canaria, 1993-1994.

PÉrez de la Riva, Juan, El Barracón y otros ensayos, La Habana, Ciencias Sociales, 1975. 1976.

PÉrez, Louis A., Lords of the mountain. Social banditry and peasant protest in Cuba, 1878-1918, Pittsburgh, University of Pittsburgh Press, 1989.

Piqueras, José Antonio, comp., Azúcar y esclavitud en el final del trabajo forzado, Madrid, Fondo de Cultura Económica, 2001.

, Sociedad civily poder en Cuba. Colonia y poscolonia, Madrid, Siglo XXI, 2005.

- La revolución democrática (1868-1874). Cuestión Social, colonialismo y grupos de presión, Madrid, Centro de Publicaciones del Ministerio del Trabajo y Seguridad Social, 1992.

y Enric Sebastiá, Agiotistas, negreros y partisanos. Dialéctica social en vísperas de la Revolución Gloriosa, Valencia, Edicions Alfons el Magnànim, 1991.

Scotт, Rebecca, La emancipación de los esclavos en Cuba. La transición al trabajo libre, 1860-1899, México, Fondo de Cultura Económica, 1989.

, "Relaciones de clase e ideologías raciales: acción rural colectiva en Loisiana y Cuba, 1865-1912”, Historia Social, núm. 22, Valencia, 1995.

Vilanova, Manuel, Estadisticas de la abolición de la esclavitud, La Habana, 1885.

FECHA DE RECEPCIÓN DEL ARTÍCULO: 5 de noviembre de 2008 FECHA DE ACEPTACIÓN Y RECEPCIÓN DE LA VERSIÓN FINAL: 17 de junio de 2010 